\title{
Duas espécies novas de Anthophora Latreille (Hymenoptera, Apidae) ${ }^{1}$
}

\author{
Danúncia Urban ${ }^{2} \&$ Gabriel A. R. Melo ${ }^{2}$ \\ ${ }^{1}$ Contribuição número 1495 do Departamento de Zoologia, Universidade Federal do Paraná. \\ 2 Departamento de Zoologia, Universidade Federal do Paraná. Caixa Postal 19020, 81531-980 Curitiba, Paraná, Brasil. \\ Bolsista do CNPq.
}

\begin{abstract}
Two new species of Anthophora Latreille (Hymenoptera, Apidae). Two neotropical Anthophorini are described and ilustrated, Anthophora (Mystacanthophora) brasiliana sp. nov. from Brasília, Brasil and Anthophora (Mystacanthophora) chulumani sp. nov. from Chulumani, Bolívia.

KEY WORDS. Anthophorini, neotropical, new species.
\end{abstract}

RESUMO. São descritos e ilustrados dois Anthophorini neotropicais, Anthophora (Mystacanthophora) brasiliana sp. nov. de Brasília, Brasil e Anthophora (Mystacanthophora) chulumani sp. nov. de Chulumani, Bolívia.

PALAVRAS-CHAVE. Anthophorini, espécies novas, neotropical.

\begin{abstract}
Anthophora Latreille, 1803 é um gênero de ampla distribuição geográfica (Michener 2000). As espécies que ocorrem na região neotropical foram colocadas por Ввоокs (1988) no subgênero Mystacanthophora, proposto no mesmo trabalho. A única espécie de Anthophora anteriormente conhecida no Brasil, Anthophora paranensis Holmberg, 1903, descrita da Argentina, tem pilosidade fulva no dorso do mesossoma e amarelo-esbranquiçada na faixa marginal dos tergos. Baseados em exemplar depositado na Coleção de Entomologia Pe. J.S. Moure, Departamento de Zoologia, Universidade Federal do Paraná, Silveira et al. (2002) afirmam que haveria mais uma espécie brasileira, proveniente do Rio de Janeiro. O exame detalhado do espécime revelou tratar-se de outro gênero de Anthophorini, Amegilla Friese, 1897, que não ocorre na região neotropical, indicando um provável erro na etiquetagem do espécime.

No presente trabalho, duas espécies sulamericanas são propostas como novas, uma proveniente de Brasília, Brasil, e a outra de Chulumani, Bolívia. Os depositários do material-tipo são os seguintes: Coleção de Entomologia Pe. J.S. Moure, Universidade Federal do Paraná, Curitiba (DZUP) e Coleção de Entomologia, Universidade de Brasília, Brasília (UnB).
\end{abstract}

\section{Anthophora (Mystacanthophora) brasiliana sp. nov.}

\section{Figs 1-2}

Diagnose. Fêmea com o integumento enegrecido e quase toda a pilosidade preta, inclusive na maior parte da cabeça; clípeo com pêlos longos, curvados para baixo, relativamente finos e com minúsculas ramificações, cerdas basais não diferenciadas das demais, não formando pente cerdoso.

Holótipo fêmea. Comprimento aproximado 12,9 mm; comprimento da asa anterior a partir do esclerito costal 9,2 mm; largura da cabeça 5,1 mm; comprimento do olho 3,75 mm. Integumento predominantemente enegrecido. Mandíbulas castanho-escuras com mácula subapical avermelhada quase até o meio; antenas castanho-enegrecidas. Tégulas translúcidas amarelo-acastanhadas; membrana alar tingida de castanho; pernas castanho-avermelhadas com os tarsômeros medianos e distais um pouco amarelados. Tergos enegrecidos, exceto zonas marginais translúcidas; esternos castanho-avermelhados.

Pilosidade preta, exceto castanho-esbranquiçada no labro, margem apical do clípeo, estria fina nas paroculares inferiores, mandíbulas e área hipostomal; na metade ventral e posterior das genas castanho-acinzentada; preta na metade dorsal das genas junto aos olhos. Preto-acinzentada nos mesepisternos e pernas, exceto pela nódoa castanho-clara no ápice das tíbias e pelas cerdas pretas nas tíbias, basitarsos medianos e posteriores.

Disco do clípeo revestido com pêlos arqueados para baixo, relativamente delgados e com ramificações minúsculas; cerdas basais não diferenciadas das demais, não formando pente; área supraclipeal com pêlos semelhantes aos do disco do clípeo e cerdas finas longas. Primeiro tergo metassomal (T1) com abundante pilosidade longa e ereta; disco de T2-5 com pêlos eretos e semi-eretos, relativamente curtos em T2-3 (0,20,23 mm) e mais longos em T4-5 (os mais longos com 0,4-0,5 mm de comprimento); faixa de pêlos decumbentes alongados na zona marginal de T1-4 e em T5 formando tufo pré-pigidial.

Holótipo fêmea. Brasil, Distrito Federal: Brasília, com as etiquetas: "Res. Ecol. [Reserva Ecológica] IBGE / Km 0 BR 251 DF [Distrito Federal] / 24 - IV a 08 - V- 81 / 3A - 62 - 4 m."; e etiqueta vermelha "HOLÓTIPO"; sem indicação de coletor (DZUP). Parátipos: uma fêmea, com os mesmos dados do holótipo (DZUP); uma fêmea, idem, exceto 05 a 17.VI.1981 

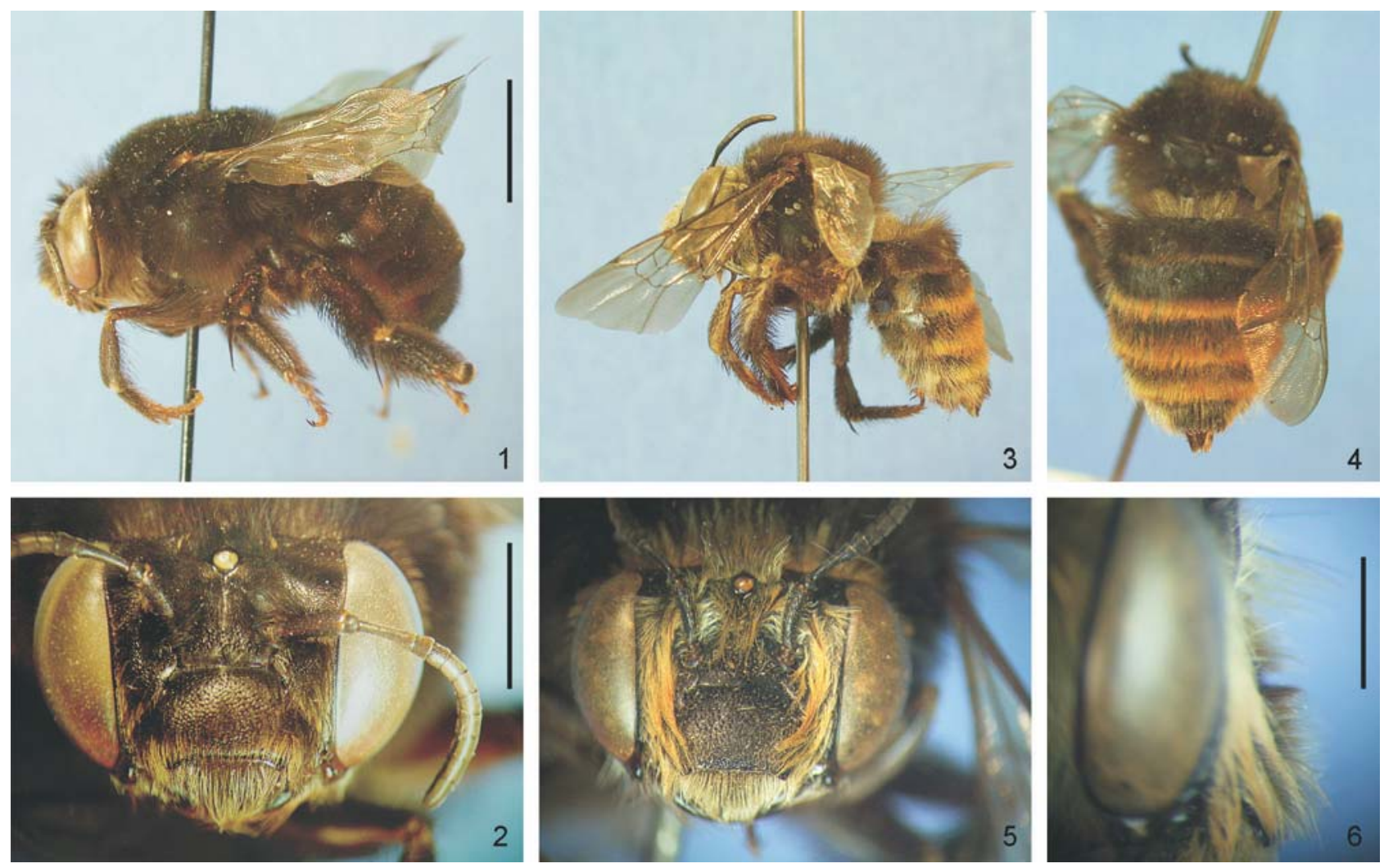

Figuras 1-6. (1-2) Holótipo de Anthophora (Mystacanthophora) brasiliana sp. nov.: (1) vista de perfil; (2) vista frontal da cabeça; (3-6) holótipo de Anthophora (Mystacanthophora) chulumani sp. nov.: (3) em perfil; (4) parte distal do mesossoma e tergos; (5) vista frontal da cabeçal (6) perfil da cabeça evidenciando as cerdas clipeais e supraclipeais. Escalas: 4,0 mm para as Figs 1, 3 e 4; 2,0 mm para as Figs 2 e $5 ; 1,0 \mathrm{~mm}$ para a Fig. 6.

(UnB); uma fêmea, Brasília, F.[Fazenda] Água Limpa, IV.1981, sem indicação do coletor, obtida em flores de Byrsonima crassa Niedenzu (Malpighiaceae) (DZUP).

Etimologia. Nome relativo ao local de coleta.

Comentário. Anthophora (Mystacanthophora) andicola Schrottky, 1911, descrita de Juliaca, Puno, Peru, embora tenha em comum com A. brasiliana sp. nov. a pilosidade enegrecida, inclusive na face, difere pelo clípeo com pente cerdoso basal e revestido com cerdas eretas dobradas na ponta.

\section{Anthophora (Mystacanthophora) chulumani sp. nov. Figs 3-6}

Diagnose. Fêmea com pilosidade esbranquiçada na cabeça, enegrecida no metasoma e com pêlos ferrugíneos nos tergos medianos; clípeo com pente cerdoso basal, revestido com cerdas eretas dobradas na ponta.

Holótipo fêmea. Comprimento aproximado 12,5 mm; comprimento da asa anterior a partir do esclerito costal 8,9 mm; largura da cabeça 4,45 mm; comprimento do olho 2,5 $\mathrm{mm}$. Integumento enegrecido, incluindo as antenas; pernas casta- nho-escuro, os tarsômeros medianos e distais das pernas anteriores castanho-claro; tégulas castanho-translúcidas; membrana alar tingida de castanho; zona marginal dos tergos translúcida, levemente amarelo-avermelhada.

Pilosidade da cabeça creme com alguma mescla de pêlos castanhos junto ao vértice e na porção mediana da fronte, logo abaixo dos ocelos; com uma tonalidade levemente fulva nas paroculares e no contorno posterior do vértice; as cerdas do clípeo, incluindo as do pente basal e da área supraclipeal, castanho-pálidas com a ponta esbranquiçada. Enegrecida no mesossoma, com estria fina de pêlos curtos esbranquiçados na base do metanoto e com um pequeno tufo castanhoavermelhado atrás das tégulas; castanho-acinzentada na face ventral dos mesepisternos; esbranquiçada nos dois artículos basais das pernas (mais evidente nas coxas anteriores), e castanha nos demais artículos, com área esbranquiçada na ponta dos fêmures e em parte da face externa das tíbias (na tíbia posterior, restritas à metade basal do bordo posterior e ao ápice). Preta no tergo basal, exceto castanho-clara em sua metade vertical, a margem posterior com fina orla de pêlos ruivos; no T2, 
preta com faixa marginal estreita de pêlos ferrugíneo-pálidos; nos dois tergos seguintes, ferrugínea com mescla de pêlos castanho-enegrecidos no terço basal; no quinto tergo, amareloesbranquiçada nos lados, disco com pilosidade predominantemente preta, tufo pré-pigidial preto.

Clípeo fortemente cerdoso, as cerdas eretas e com a ponta muito fina curvada para baixo, as do pente basal também com a ponta finíssima voltada para baixo; área supraclipeal com cerdas semelhantes às do clípeo. Tergos com pilosidade densa, semi-ereta no disco e decumbente na zona marginal; T1 com pêlos muito longos (0,6-0,8 mm); no disco de T2-3, com cerca de 0,3-0,35 mm de comprimento; os mais longos em T45 , com cerca de $0,3 \mathrm{~mm}$.

Holótipo fêmea. Bolívia, La Paz com as etiquetas: "Chulumani - 1800 m. / Yungas La Paz / I - 1948 / Pe. G. Williner leg."; e etiqueta vermelha "HOLÓTIPO"; (DZUP); três parátipos fêmeas com os mesmos dados de coleta (DZUP).

Etimologia. Nome aposto, relativo à localidade-tipo.

Comentários. A. chulumani sp. nov. é a única espécie sulamericana de Anthophora com os tergos medianos ferrugíneopilosos. FrIESE (1922) publicou duas espécies de Anthophora de Tarata, Bolívia: A. albiceps com pilosidade branca na cabeça e preta no corpo, tergos 1-5 com franja preta, e A. boliviensis, que considerou semelhante a A. albiceps porém com faixa pilosa amarelada nos tergos 2 a 4 . As duas espécies bolivianas foram colocadas na sinonímia de Anthophora (Mytacanthophora) arequipensis Brèthes, 1920, por BROокs (1988).

\section{AGRADECIMENTOS}

Ao Prof. Reginaldo Constantino, da Universidade de Brasília, pelo empréstimo do material para estudo e doação de espécimes para a coleção do DZUP.

\section{REFERÊNCIAS BIBLIOGRÁFICAS}

BRoокs, R.W. 1988. Systematics and phylogeny of the anthophorine bees (Hymenoptera: Anthophoridae; Anthophorini). University of Kansas Science Bulletin, Lawrence, 53 (9): 436-575.

FrIESE, H. 1922. Neue Arten der Anthophorinae (Hym.). Konowia, Wien, I (1-2): 59-66.

Michener, C.D. 2000. The Bees of the World. Baltimore, Johns Hopkins University Press, 913p.

Silveira, F.A., G.A.R. Melo \& E.A.B. Almeida. 2002. Abelhas Brasileiras: Sistemática e Identificação. Belo Horizonte, F.S. Silveira, 253p.

Recebido em 24.V.2004; aceito em 11.I.2005.

Revista Brasileira de Zoologia 22 (1): 81-83, março 2005 